\title{
Taguchi Optimization of Carboxymethylation Process and Effect Reaction Efficiency on Swelling Capacity
}

\author{
Ernest C. Agwamba ${ }^{1 *}$, Lawal G. Hassan², Achor Muhammad², and Abdullahi M. Sokoto². \\ ${ }^{1}$ Department of Chemical Sciences, Faculty of Sciences, Clifford University, Owerrinta \\ Abia State, Nigeria \\ ${ }^{2}$ Department of Pure and Applied Chemistry, Faculty of Science, Usmanu Danfodiyo University Sokoto \\ Sokoto, Nigeria \\ ${ }^{3}$ Department of Pharmaceutics, Faculty of Pharmaceutical Science, Usmanu Danfodiyo University Sokoto \\ Sokoto, Nigeria \\ ${ }^{*}$ Corresponding author's email: agwamba.ernest [AT] gmail.com
}

\begin{abstract}
The aim of this research paper was to ascertain the optimum conditions required to economical synthesis carboxymethylated starch using experimental design technique by Taguchi for Larger-is-better and smalleris better of reaction efficiency (RE). Orthogonal Array method was utilized in the design of the experiment which consisted of eighteen (18) runs based on three (3) independent Factors which are; Sodium hydroxide (NaOH) with three concentration levels $(1,1.5$, and $2.0 M)$, Sodium monochloroacetate (SMCA) with three concentration levels $(1,1.5$, and 2.0M) and Reaction Time (T) with two (2) levels (2 and 4 hours) respectively and the response is reaction efficiency (R.E). The result obtained from the experiment was interpreted using the Taguchi method of larger-is-better and smaller-is-better was apply to estimate the Response for Signal-to-Noise Ratios. The analysis showed that for larger-isbetter, the optimal condition to obtain high reaction efficiency (R.E.) of 9.97\%, will require $\mathrm{NaOH}$ at $2.0 \mathrm{M}, \mathrm{SMCA}$ at $1.0 \mathrm{M}$, at reaction period of, while for smaller-is-better, the optimal condition to obtain low reaction efficiency (RE) of $1.93 \%$, will required the concentration of $\mathrm{NaOH}(\mathrm{aq})$ and $\mathrm{SMCA}(\mathrm{aq})$ to be $1.5 \mathrm{M}$ and $1.5 \mathrm{M}$ with a reaction period $(\mathrm{T})$ of 4 hours respectively. The result was also study the influence of variable SMCA (aq) and $\mathrm{NaOH}(\mathrm{aq})$ concentrations on swelling capacity (SC) at reaction time of 2 hours. The result shows that $2 \mathrm{M} \mathrm{NaOH}$ is the optimum concentration for carboxymethyl starch (CMS) synthesis. .Significant difference was ascertained using Tukey method, and at 95\% Confidence level.
\end{abstract}

Keywords--- Taguchi methods, Optimization, Carboxymethyl starch (CMS), Reaction efficiency (R.E), Swelling Capacity (SC).

\section{INTRODUCTION}

Carboxymethylation of polysaccharides is an environmental friendly process to convert native polysaccharides into more versatile useful green products. Starch and cellulose are the two major biomaterials that are utilized in making commercially available carboxymethyl products known as carboxymethyl starch (CMS) and carboxymethyl cellulose (CMC) via chemical modification. The chemical modification has become the most convenient route to changing the chemical nature and physical properties of native polysaccharides in order to improve on the inherent undesirable properties[1] (Kavlani et al., 2012). CMS is produced by Williamson's ether synthesis in a two-step reaction, where the mechanism is a double nucleophilic substitution reaction; the first step which is alkalization of starch utilizing an aqueous solution of sodium hydroxide to an intermediate product called sodium glycolate, the second step is etherification process that involves the sodium glycolate and sodium monochloroacetate reacting to give starch carboxymethylate. Degree of substitution indicates the mean amount of carboxymethyl group per Anhydrous Glucose Unit (AGU). The AGU is monomer unit of starch has three hydroxyl groups, the degree of displacement hydroxyl group by the carboxymethyl group is the measure of DS, and the maximum obtainable DS is three (3). The Carboxymethyl starch is versatile product that has found application in various industries from pharmaceuticals, petroleum, paper, cosmetics, pastries, food e.t.c. due to its ability to improve clarity, swelling capacity, absorption capacity, among others that are too numerous to mention.[2], [3], [4], [5], [6], [7].

Study by Tatongjai and Lumdubwong [8] indicates that CMS gel and film has significantly enhanced transparency, and storage stability. In cold water, the solubility of CMS is significantly enhanced with increases in value of substitution (DS), and the most of physicochemical characters are remarkable altered such as: water absorption which is described by hydration capacity and swelling capacity, adhesiveness and film forming properties are improved simultaneously [9]. 
Carboxymethylated starch derivatives exhibited reduced temperature of gelatinization, characteristic change in rheology and $\mathrm{pH}$ stability [10], [11] when compared to native starch.

In research industries, the essence of optimization is to decrease experimental time, and numbers runs, select optimal conditions to maximize profit, thereby cutting production cost, reduce waste of chemicals, raw materials, ultimately reducing product and service rejection rate, with an overall enhanced customer satisfaction.

Optimization can be defined as a process of ascertaining those values of controllable factors referred to as independent variable that results to the most desired responses also known to as dependent variable. A vivid image of all suitable approach must be put in perspective, when an optimization studies is to be embarked on.

Most experiment are designed using one-factor at time method (OFAC) which is usually cumbersome, confusing, ambiguous, and non-predictable responses are obtainable because it doesn't follow any statistical model in its design.

Experimental Designs (D.O.E) are utilized to plan overall experimental processes and create experiments for different phases of the process used to fit a model to a data, analyze the factor effects, and ascertain the direction of the process under evaluation. In essences the importance of experimental designs is to plan, create, analyze and interpret designs to obtained optimum condition, and the major known designs are Factorial, Response Surface, Mixture, and Taguchi [12].

Numerous researchers have employed the Taguchi technique because it is an efficient route to the designing of superb experimental systems. Also it gives an easy, efficient and step wise approach to improve quality, affordability and enhance processes and product design ([13]. This technique is consistent method for designing excellent reliable process and suitable conditions over variable factors. This design is utilized in decreasing the counts of experimental runs by applying orthogonal arrays.

Khuri et al., [14], described that Taguchi methods has two types independent factors in experiments,

i. Control factors: easy to control and

ii. Noise factors: Not easy to control.

These Noise factors that are not easy-to-control cause fluctuation in the outcome of experimental or production process. The main intention of parameter design is to ascertain the settings of the control factors for which the process response is robust to the divergence in the system induced by the noise factors. To accomplish this purpose, the application of crossed arrays by crossing an orthogonal array of control variables (inner array) with an orthogonal array of noise variables (outer array) was put forward by Taguchi. He pinpointed that every experiment has three unique aims which are given as follows: 1. The smaller, the better: This is applied when the goal is to minimize the response

2. The larger, the better: This is applied when the aim is to maximize the response

For each of the various aim, Taguchi defined performance criteria referred to as signal-to-noise $(\mathrm{S} / \mathrm{N})$ ratios which considered both the process average and the variance.

\subsection{Taguchi Experimental Design}

\section{MATERIALS AND METHODS}

The experimental design was performed by applying Taguchi Orthogonal Array (1 23 3) with columns of L18 ( $\left.2^{\wedge} 13^{\wedge} 7\right)$ was applied in this design of experiment as shown in Table 1. The experimental design has 18 runs with 3 factors, which are; Time with 2 levels ( 2 and 4 hours), $\mathrm{NaOH}_{(\text {aq) }}$ with 3 levels $\left(1,1.5\right.$, and $2 \mathrm{~mol} / \mathrm{dm}^{3}$ ) and SMCA with 3 levels (1, 1.5, and $2 \mathrm{~mol} / \mathrm{dm}^{3}$ ) as shown in table 1 below.

The exact optimal condition for obtaining CMS with upper (larger-is-better) and lower (small-is better) level of DS will be ascertained by Taguchi technique as stated earlier, using Statistical software (Minitab17). The signal-to-noise (S/N) ratio will be analyzed for every factor level combination. For each of the two different goals, Taguchi defined the S/N ratios as follows: Equation (1) and (2) below are the mathematical expressions for the larger-is-better, and smaller-is-better S/N ratio applying base $10 \log$ respectively:

$\mathrm{S} / \mathrm{N}=-10 \mathrm{x} \log 10\left[\mathrm{sum}\left(1 / \mathrm{Y}^{2}\right) / \mathrm{n}\right]$-----------------------------------(1)

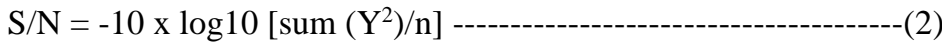

Where $\bar{Y}$ is the response mean and $\mathrm{S}^{2}$ is the sample variance, $\mathrm{Y}$ is responses for the given factor level combination and $\mathrm{n}$ $=$ number of responses in the factor level combination. 
Table 1: The Experimental Design of Independent Variables using Taguchi Methods

\begin{tabular}{lccc}
\hline Sample & Time (Hr) & $\begin{array}{c}\text { SMCA } \\
\left(\mathbf{m o l} / \mathbf{d m}^{\mathbf{3}}\right)\end{array}$ & $\begin{array}{c}\mathbf{N a O H} \\
\left(\mathbf{m o l} / \mathbf{d m}^{\mathbf{3}}\right)\end{array}$ \\
\hline C1 & 2 & 1 & 1 \\
C2 & 2 & 1 & 1.5 \\
C3 & 2 & 1 & 2 \\
C4 & 2 & 1.5 & 1 \\
C5 & 2 & 1.5 & 1.5 \\
C6 & 2 & 1.5 & 2 \\
C7 & 2 & 2 & 1 \\
C8 & 2 & 2 & 1.5 \\
C9 & 2 & 2 & 2 \\
C10 & 4 & 1 & 1 \\
C11 & 4 & 1 & 1.5 \\
C12 & 4 & 1 & 2 \\
C13 & 4 & 1.5 & 1 \\
C14 & 4 & 1.5 & 1.5 \\
C15 & 4 & 1.5 & 2 \\
C16 & 4 & 2 & 1 \\
C17 & 4 & 2 & 1.5 \\
C18 & 4 & 2 & 2 \\
\hline & & &
\end{tabular}

\subsection{Extraction of Starch}

Starch isolate was obtained from mango seed kernel employing the technique described in [15], [16], [17], and [18] with some modification in the method where necessary. Starch was extract using hot water extraction method. $100.00 \mathrm{~g}$ of powdered mango seed kernel was soaked in a $1000 \mathrm{~cm}^{3}$ beaker containing $200 \mathrm{~cm}^{3}$ of deionized water in a thermostatic water bath (WBH 6/FL, Genlab Thermal Eng., UK) at a constant temperature of $40^{\circ} \mathrm{C}$ for about 24 hours. One portion of the suspended powdered mango seed kernel and three portions of deionized water were homogenized for 3 minutes at moderate and fast speed. The resultant slurry was filtered with a double layer of muslin cloth and then centrifuged (TDL4, Ningbo Hinotel Tech, China) at $5000 \mathrm{rpm}$ for 20 minutes. The supernatant was poured out and removed while the deposit re-suspended in surplus $0.02 \% \mathrm{NaOH}_{\text {(aq) }}$ to eliminate any left-over proteins and phenolic compounds. After standing for 4 hours the supernatant was poured out and removed. The process was replicated about 6-8 times till the supernatant became colourless. Final white sediment was suspended in deionized water and before been filtered through $0.045 \mathrm{~mm}$ sieve, neutralized with deionized water to $\mathrm{pH}$ 7.0, and finally filtered on Buchner funnel. The filtered cake was dried in an electric oven (Nuve Oven/FN-055) at $70^{\circ} \mathrm{C}$ for 12 hour, and the resulting dry starch was grounded to fine powdered particles with electric blender (Binatone blender), weighed and stored in an air-tight container for future utilization.

\subsection{Synthesis of Carboxymethyl Starch}

Organic slurry technique of modification was applied as stated by Lawal et al., [11]. The unmodified starch isolate derived from the mango kernel $(10.0 \mathrm{~g})$ was suspended in 2-propanol $\left(200 \mathrm{~cm}^{3}\right)$ placed in a beaker. $20 \mathrm{~cm}^{3}$ of various concentrations $(1.0 \mathrm{M}, 1.5 \mathrm{M}$ or $2.0 \mathrm{M})$ of sodium hydroxide was introduced. The mixture was homogenized at a regulated temperature $\left(30^{\circ} \mathrm{C}\right)$ for 10 minutes. $80 \mathrm{~cm}^{3}$ of various concentrations $(1.0 \mathrm{M}, 1.5 \mathrm{M}$ or $2.0 \mathrm{M})$ of Sodium monochloroacetate was introduced and homogenized continuously up to the stipulated period in the experimental design ( 2 or 4 hours) in shakerwater bath (Uniscope/DKZ-2, Hanna, Italy). The $\mathrm{pH}$ (Jenway $3510 \mathrm{pH}$ meter) of the mixture was attuned to about 5.0 by introducing glacial acetic acid at 50\% concentration. The synthesized carboxymethyl starch was filtered, and washed with $80 \%$ aqueous ethanol until the $\mathrm{pH}$ of the residue was neutral (7.0) and dried in an oven (Nuve Oven/FN-055) at 50 ${ }^{\circ} \mathrm{C}$ for 6 hours. Fine particles of the dried carboxymethyl starch were obtained by passed it through a 100-mesh sieve. This process was replicated 18 times with variable concentration of $\mathrm{SMCA}_{(\mathrm{aq})}, \mathrm{NaOH}_{(\mathrm{aq})}$, and reaction time and the products of the synthesis were labeled $\mathrm{C} 1$ to $\mathrm{C} 18$.

\subsection{Determination of the Reaction Efficiency $(R E)$}

The degree of substitution (DS) was determined with flame atomic absorption spectrometry (Corning 400, Ciba-Corning, USA) with respect to the level of sodium in the CMS as described by Lawal et al.[19]. The sample (50.00 $\mathrm{mg}$ ) was dissolved in undiluted nitric acid $\left(4 \mathrm{~cm}^{3}\right)$ in a glass vessel and heated with a hot plate. The digested sample was filled-up to $100 \mathrm{~cm}^{3}$ mark with deionized water before analysis with the spectrometer. The flame composition was air-acetylene while the wavelength of sodium was $589.0 \mathrm{~nm}$. The degree of substitution was determined as follows:

$$
D S=\frac{162 \% \mathrm{Na}}{(2300-80 \% \mathrm{Na})}
$$


$\% \mathrm{Na}$ of the unmodified starch was predetermined by flame atomic absorption spectrometry and it was corrected in the CMS derivative.

$$
R . E=\frac{D S}{D S t} \times 100 \%----------(i i)
$$

Since DS of 3 is the maximum any starch carboxymethylated can attain, the Reaction efficiency (R.E) becomes the percentage comparison between the Degree of Substitution(DS) usually obtained from the synthesis, and the theoretical degree of substitution ( $\mathrm{DSt}=3$ ), which is show the maximum degree to which the carboxymethyl group can replace hydroxyl group on the starch molecule.

\subsection{Determination of Swelling Capacity}

Okhamafe et al.,[20] technique was adopted. $1 \mathrm{~g}$ of CMS was measured into a calibrated centrifuging tube and tapped for 500 times consecutively and the volume occupied by the CMS was measured to be $\mathrm{V}_{500}$. The distilled water was added to the CMS in the tube, sealed, and agitated vigorously before centrifuging at $5000 \mathrm{rpm}$ for 20 minutes. The water on top of the CMS after centrifuging was discarded and the new volume occupied by the hydrated CMS was measured to $\mathrm{V}_{2}$.

The swelling capacity was calculated using the mathematical equation below (iii).

$$
\text { Swelling capacity } \%(\mathrm{~S})=\left(\mathrm{V}_{2}-\mathrm{V}_{500}\right) / \mathrm{V}_{500}
$$

Where $\mathrm{S}$ is the $\%$ swelling capacity, $\mathrm{V}_{2}$ is the volume of the hydration or swollen material and $\mathrm{V}_{500}$ is the tapped volume of the material prior to hydration.

\section{RESULTS}

Table 2: The Independent Variables, and Response variable (R.E) and Swelling capacity (SC)

\begin{tabular}{cccccc}
\hline & \multicolumn{3}{c}{ Experimental Factors } & \multicolumn{2}{c}{ Responses } \\
\hline Sample & $\begin{array}{c}\text { Time } \\
(\mathbf{H r})\end{array}$ & $\begin{array}{c}\text { SMCA } \\
\left(\mathbf{m o l} / \mathbf{d m}^{\mathbf{3}}\right)\end{array}$ & $\begin{array}{c}\mathbf{N a O H} \\
\left(\mathbf{m o l} / \mathbf{d m}^{\mathbf{3}}\right)\end{array}$ & $\mathbf{R E}(\boldsymbol{\%})$ & $\begin{array}{c}\text { SC } \\
(\mathbf{v} / \mathbf{v})\end{array}$ \\
C1 & 2 & 1 & 1 & $6.1 \pm 0.173$ & $144 \pm 0.02$ \\
C2 & 2 & 1 & 1.5 & $8.6 \pm 0.063$ & $54 \pm 0.03$ \\
C3 & 2 & 1 & 2 & $9.97 \pm 0.078$ & $46 \pm 0.004$ \\
$*$ C3 & 2 & 1 & 2.5 & NA & $45 \pm 0.032$ \\
C4 & 2 & 1.5 & 1 & $5.2 \pm 0.245$ & $216 \pm 0.04$ \\
C5 & 2 & 1.5 & 1.5 & $6.7 \pm 0.114$ & $159 \pm 0.018$ \\
C6 & 2 & 1.5 & 2 & $8.6 \pm 1.172$ & $94 \pm 0.072$ \\
$*$ C6 & 2 & 1.5 & 2.5 & NA & $85.7 \pm 0.002$ \\
C7 & 2 & 2 & 1 & $4.63 \pm 0.066$ & $273 \pm 0.16$ \\
C8 & 2 & 2 & 1.5 & $5.73 \pm 0.049$ & $288 \pm 0.03$ \\
C9 & 2 & 2 & 2 & $10.3 \pm 0.092$ & $322 \pm 0.59$ \\
$*$ C9 & 2 & 2 & 2.5 & NA & $334 \pm 0.004$ \\
$*$ C10 & 2 & 2.5 & 1 & NA & $336 \pm 0.102$ \\
$*$ C11 & 2 & 2.5 & 1.5 & NA & $135 \pm 1.04$ \\
$*$ C12 & 2 & 2.5 & 2 & NA & $115 \pm 0.011$ \\
$*$ C13 & 2 & 2.5 & 2.5 & NA & $113 \pm 0.224$ \\
C10 & 4 & 1 & 1 & $5.47 \pm 0 . .069$ & NA \\
C11 & 4 & 1 & 1.5 & $7.13 \pm 0.584$ & NA \\
C12 & 4 & 1 & 2 & $8.6 \pm 0.399$ & NA \\
C13 & 4 & 1.5 & 1 & $3.3 \pm 0.130$ & NA \\
C14 & 4 & 1.5 & 1.5 & $1.93 \pm 0.062$ & NA \\
C15 & 4 & 1.5 & 2 & $1.3 \pm 0.035$ & NA \\
C16 & 4 & 2 & 1 & $4.77 \pm 0.175$ & NA \\
C17 & 4 & 2 & 1.5 & $2.7 \pm 0.057$ & NA \\
C18 & 4 & 2 & 2 & $5.73 \pm 0.632$ & NA \\
\hline
\end{tabular}

R.E = Reaction efficiency, SMCA= sodium monochloroacetate, $\mathbf{S C}=$ Swelling Capacity, NA= Not ascertained or measured, $* \mathbf{C}=$ levels of the factors not given by Taguchi design. 
Taguchi Analysis: \% RE versus Time (Hr), SMCA, NaOH

The result for the Taguchi analysis for the larger-is-better and smaller-is-better are shown in Figure 2 and 3 below.

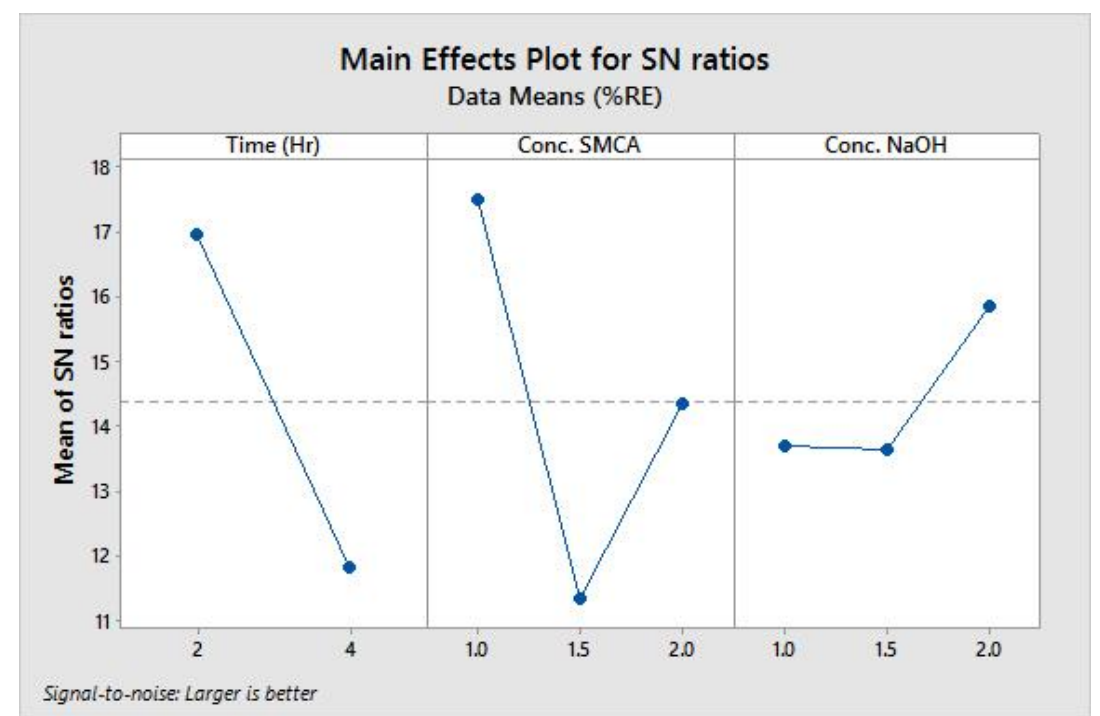

Figure 1: Main Effects Plot for Signal to Noise ratios for Larger-is better

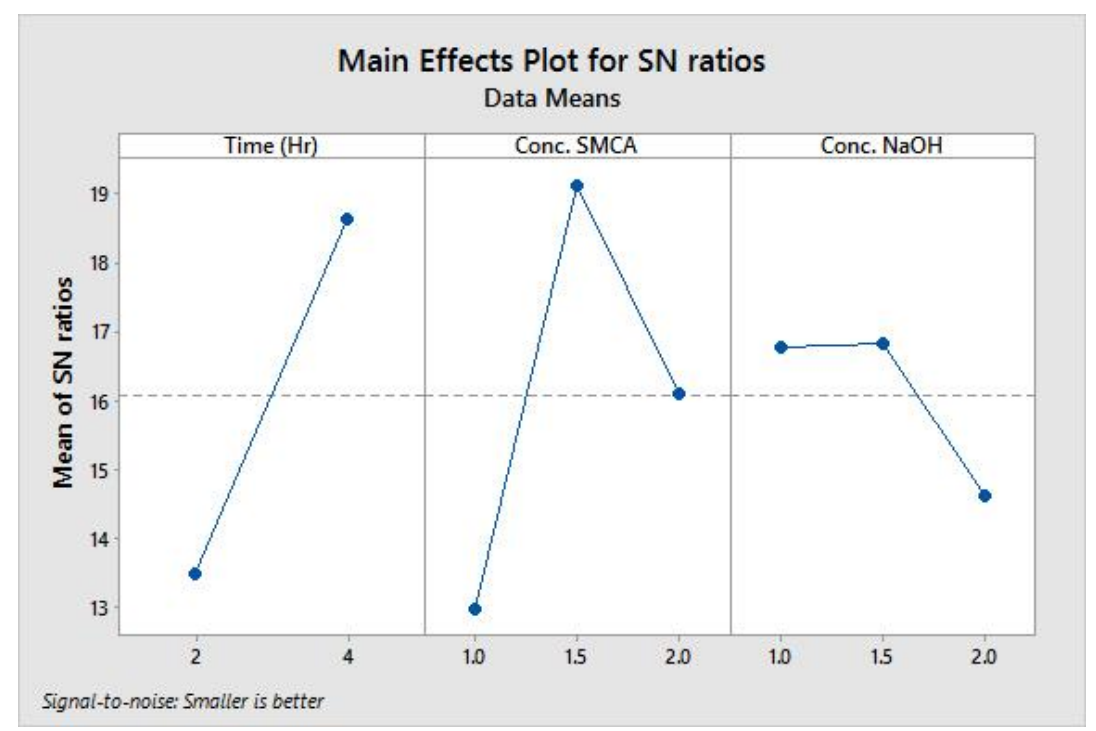

Figure 2: Main Effects Plot for Signal to Noise ratios for Smaller-is better 


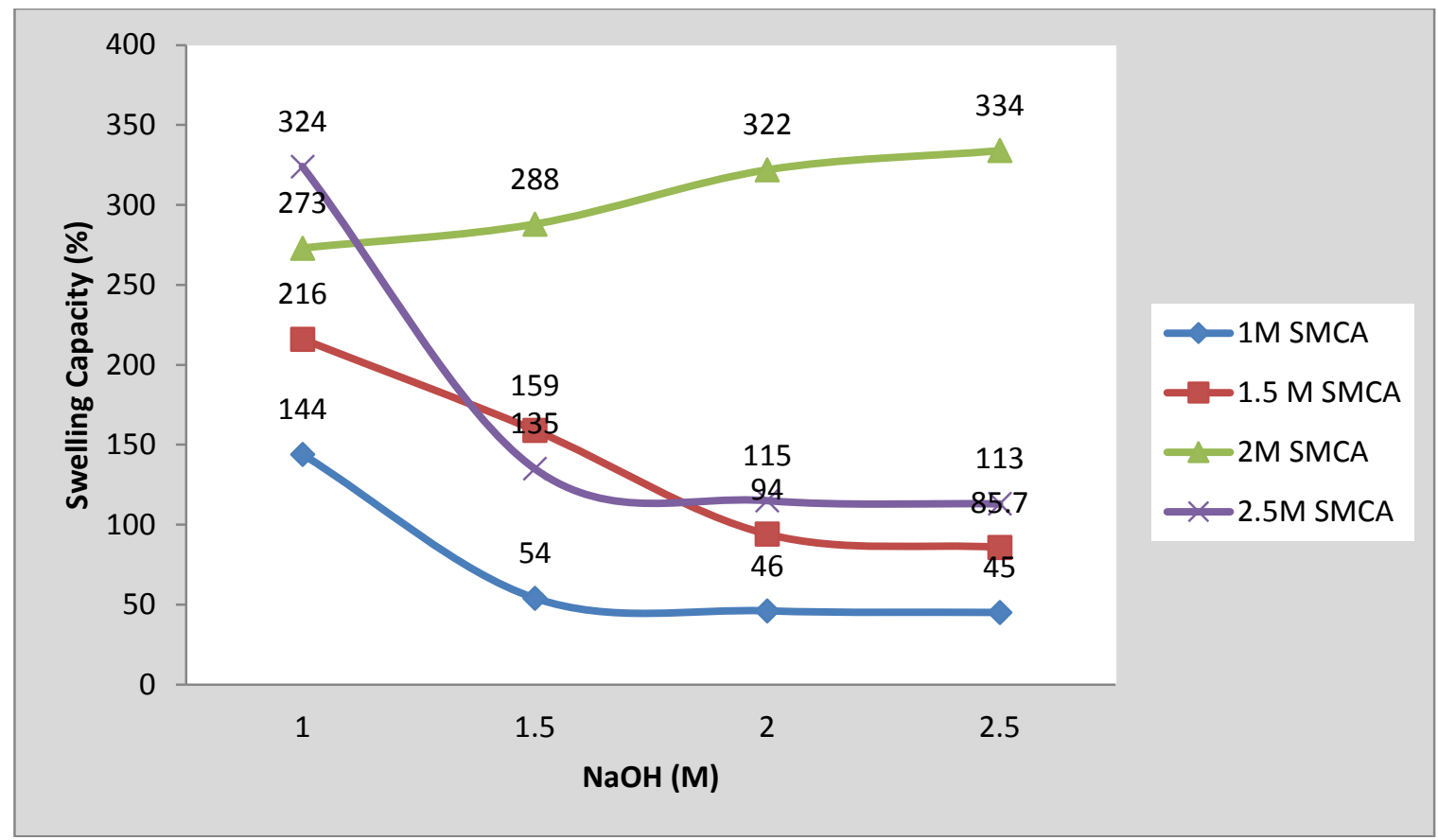

Figure 3: Effect of Variable concentration of $\mathrm{NaOH}$ (aq) on swelling capacity of Carboxymethyl starch

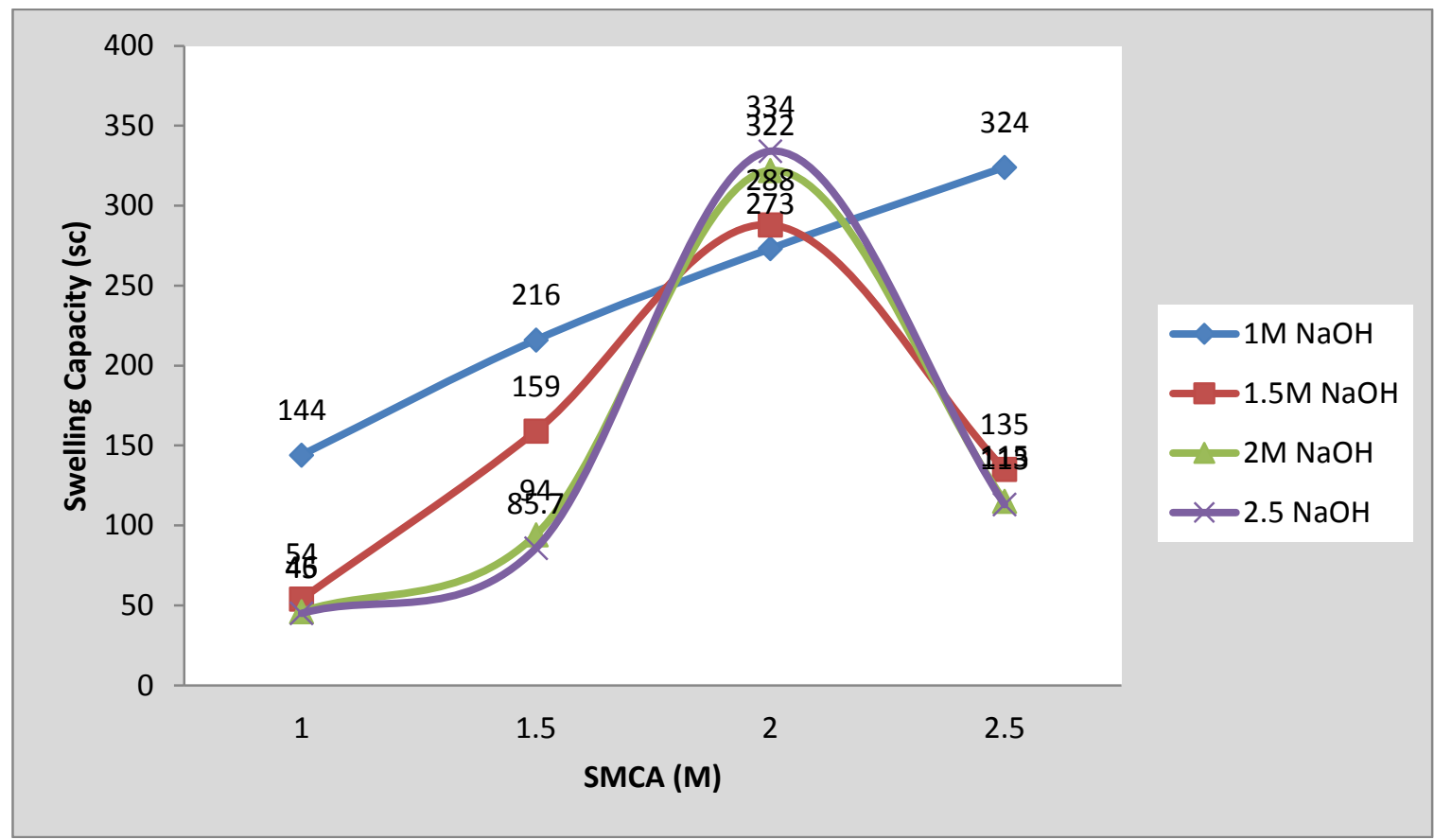

Figure 4: Effect of Variable Concentration of SMCA (aq) on swelling capacity of Carboxymethyl starch 


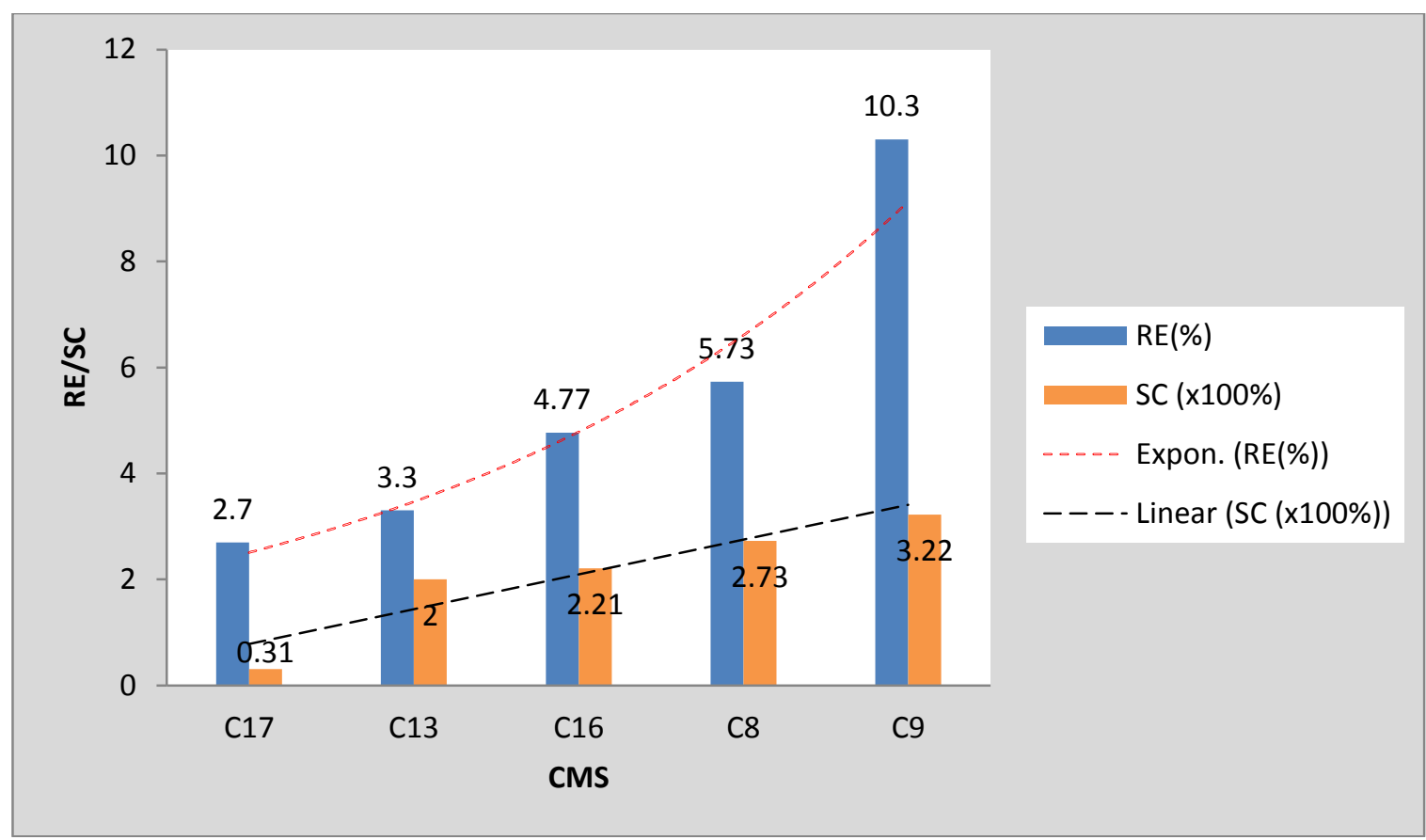

Figure 5: Effect of Reaction efficiency (RE) on Swelling Capacity (SC)

\section{DISCUSSION}

The optimization result from Main Effect plot for Signal to noise (S/N) ratios (Figure 1) and main effect plot for mean (Figure 2) using Taguchi method, has shown that the condition for optimum yield of carboxymethyl starch (C3) with reaction efficiency (R.E) of $9.97 \%$ was obtained for larger-is-better, at reaction time two (2) hours, when the concentration of Sodium monochloroacetate (SMCA) was $1.0 \mathrm{M}$, and concentration sodium hydroxide $(\mathrm{NaOH})$ was $2.0 \mathrm{M}$. The ANOVA analysis of reaction efficiencies, indicate that $\mathrm{C} 3(9.97 \%)$ show no significant difference from $\mathrm{C} 9(10.27 \%)$ despite having a slight higher value. The exact amount of conc. SMCA $2.0 \mathrm{M}$ required to synthesis C9 will result to high cost, with significant reduction in production cost either in small or large scale.

The optimum conditions for carboxymethylation for smaller-is-better, from the Figure 3 shows that time of 4 hours, SMCA at $1.5 \mathrm{M}$, and $\mathrm{NaOH}$ of $1.5 \mathrm{M}$, are the optimum conditions required to obtain a reaction efficiency of $1.93 \%$. As shown in table 2.0, it indicates that C15 (1.3\%) is lower, and shows significant difference in reaction efficiency with C13 (1.93\%). It is more economical to synthesised C14 instead of C15 as described by smaller-is-better Taguchi model and this can be attributed to the higher concentration of $\mathrm{NaOH}(2.0 \mathrm{M})$ required to synthesize $\mathrm{C} 15$, which will in industrial application results to increased production cost.

From Figure 3, the result shows that swelling capacity at $1 \mathrm{M} \mathrm{SMCA}_{(\mathrm{aq})}$ decreases as the concentration of the $\mathrm{NaOH}_{(\mathrm{aq})}$ increases, similar with $2 \mathrm{M} \mathrm{SMCA}_{(\text {aq) }}$ the same decreasing effect was observed with increased $\mathrm{NaOH}_{(\mathrm{aq})}$ concentration, but at a much higher swelling capacity. When swelling capacity was observed at $2 \mathrm{M} \mathrm{SMCA}_{(\mathrm{aq})}$ it shows a steady increasing effect, with increase in the concentration of $\mathrm{NaOH}_{(\mathrm{aq})}$ even at a significantly higher swelling capacity compared to $\mathrm{SMCA}_{(\mathrm{aq})}$ at $1,1,5,2.5 \mathrm{M}$. for $2.5 \mathrm{M} \mathrm{SMCA}_{(\text {aq) }}$ the swelling capacity decreases with increase in $\mathrm{NaOH}$ concentration just as observed for $1 \mathrm{M}$, and $1.5 \mathrm{M} \mathrm{SMCA}_{\text {(aq) }}$.

Figure 4 shows that at $1 \mathrm{M} \mathrm{NaOH}_{(\mathrm{aq})}$ the swelling capacity of the CMS increases significantly with increase in the concentration of $\mathrm{SMCA}_{(\mathrm{aq})}$ from 1 to $2.5 \mathrm{M}$. while at $1.5,2$, and $2.5 \mathrm{M} \mathrm{NaOH}_{(\mathrm{aq})}$ also shows an increase in the swelling capacity CMS with increase in $\mathrm{SMCA}_{(\mathrm{aq})}$ concentration from 1 to $2 \mathrm{M}$, which suddenly and significantly decrease when the concentration of $\mathrm{SMCA}_{(\mathrm{aq})}$ was increased to $2.5 \mathrm{M}$. This observation could be due to increase side reaction between $\mathrm{NaOH}_{(\mathrm{aq})}$ at $1.5,2$, or $2.5 \mathrm{M}$, and $\mathrm{SMCA}_{(\mathrm{aq})}$ at $2.5 \mathrm{M}$. the highest swelling capacity obtained was $334 \%$ which corresponded to the carboxymethylated mango starch synthesize with $2 \mathrm{M} \mathrm{SCMA}_{(\mathrm{aq})}$, and $2 \mathrm{M} \mathrm{NaOH}_{(\mathrm{aq})}(\mathrm{aq})$ per anhydrous glucose unit, which is approximately close to the optimum conditions predicted by Taguchi methods since C3 and C9 has no significant difference in reaction efficiency.

Swelling capacity is one of the most vital physicochemical properties of carboxymethylated polysaccharides, as the increase in carboxymethylation results to a significant alteration and enhancement the extent of the solubility and hydration capacity of the[20] thereby allowing the material to hold more water molecules within its modified matrices i.e. improved hydration capacity. This will in turn results to a significant measurable increase in the volume occupied by the carboxymethylated polysaccharides. Other studies has shown that increasing the degree of substitution results to increase in the swelling capacity, and hydration capacity due to increase in the solubility of the polysaccharide when compared to 
the unmodified one [9]. The result observed is also in accordance with outcome obtained by Tatongjai and Lumdubwong [8], which indicated in CMS solubility in cold water, with increase in the DS which is directly related to R.E.

Therefore swelling capacity is a physicochemical property of polysaccharide that is directly dependent on degree of substitution i.e. reaction efficiency (RE), which is similar to what is observed in Figure 5 of this study, that the swelling capacity increases with respect to gain in the reaction efficiency.

\section{CONCLUSION}

The optimization of carboxymethylation process is very important, as it help ascertained optimally conditions for the synthesis of CMS, without extensive and unnecessary numbers of experimental run, cut wastage of reagents, reduced production time and ultimately cut production cost. The optimal conditions for the larger-is-better show that it is more profitable to produced M3 with R.E of 9.97\% than C9 with R.E of 10.27\%. Also we can conclude on the same premise for the Smaller-is-better that it's more economical or profitable to synthesized C14 with R.E 1.93\%. It can be concluded that increase in the reaction efficiency has a direct effect on the swelling capacity of the carboxymethyl mango starch.

\section{REFERENCES}

[1] Kavlani N., Sharma V., and Singh L.; "Various Techniques for the modification of starch and the applications of its Derivatives”. International Research Journal of Pharmacy, vol. 3, Iss.5, pp. 25-31, 2012.

[2] Gander B., Gurny R., Doelker E.. "Effect of Tablet Disintegration on the Release and Absorption of an Insoluble Drug Model”. Acta Pharmaceutical Technology, vol. 31, iss.2, pp.77-84, 1985.

[3] Zhang, D. F., Ju, B. Z., Zhang, S. F., Yang, J. Z. "Progress in the synthesis and application of green chemicals, carboxy methyl starch sodium". In proceeding of. 3rd International Conference on Functional Molecules, pp.25-30, 2003.

[4] Abbas, K.A., Khalil S.K., and Hussin A.S.M. "Modified Starches and Their Usages in Selected Food Products: A Review Study". Journal of Agricultural Science, vol.2, no. 2, pp. 23 -34, 2010.

[5] Wandrey, C., Bartkowiak, A., Harding, S. E., Zuidam, N. J., Nedovic, V. A. "Encapsulation Technologies for Active Food Ingredients and Food Processing”, Springer, USA, pp .31-100, 2010.

[6] Kozich, M. and Waston, M. "Applications of chemically modified starch". In proceeding of $63^{\text {rd }}$ Starch Convention, pp. 2-8, 2012.

[7] Minaev K.M., Martynova D.O., Zakharov A.S., Sagitov R.R., Ber A.A., and lyanova1 O.S.U., "Synthesis of Carboxymethyl Starch for increasing drilling mud quality in drilling oil and gas wells". In proceeding of $43^{\text {rd }}$ IOP Conference. Series on Earth and Environmental Science, 2016.

[8] Tatongjai, J., and Lumdubwong, N., "Physicochemical properties and textile utilization of low- and moderatesubstituted carboxymethyl rice starches with various amylose content". Carbohydrydrate. Polymer, vol.81, pp. 377$384,2016$.

[9] Zhou, X., Yang, J., Qian, F., Qu, G., "Synthesis and application of modified starch as a shell-core main adhesive in a foundry". Journal Applied Polymer Science, vol. 116, pp. 2893-2900, 2010.

[10] Bhattacharyya, D., Singhal, R. S., Kulkarni, P. R., "Physicochemical properties of carboxymethyl starch prepared from corn and waxy amaranth starch". Carbohydrate Polymer, vol.27, pp. 167-169, 1995.

[11] Lawal, O. S., Lechner, M. D., Hartmann, B., Kulicke, W. M., "Carboxymethyl cocoyam starch: Synthesis, characterization and influence of the reaction parameters". Starch/Sta“rke, vol.59, pp. 224-233, 2007.

[12] Minitab17(2013). Minitab Inc. www.mintab.com/assistant. (online)

[13] Bhaduria1 O.S., Goyal S., Premanand S. C., "Application of Taguchi Method for Optimization of Process Parameters for Minimum Surface Roughness in Turning Of 45c8". International Journal Of Current Engineering And Scientific Research, vol.3, Iss.1, pp. 61-68, 2016.

[14] Khuri, A.I., and Mukhopadhyay S., "Response surface methodology”. Advanced Review, vol.2, pp.128-149, 2010.

[15] Chavan U.D., Shahidi, B.G., Kadam, S.S and Amarowicz, A., "Isolation and characterization of Starch from Horse Gram”. Africa Journal of Food Science and Technology, vol.1, no.3, pp. 64-67, 2010.

[16] Kevate, B.N., Chavan, U.D., Kadam, S.S., Chavan, J.K. and Amarowicz, R., "Isolation and characterization of starch from Moth Bean”. African Journal of Food Science and Technology, vol.1, no.3, pp. 68 -70, 2010.

[17] Uba, A., Izuagie, T., Hassan, L. G., Achor, M. and Sahabi, D. M., "Characterization of starch isolated from Mangifera indica seeds". Nigerian Journal of Basic and Applied Science, vol.19, no.2, pp. 224-230, 2011.

[18] Hassan, L.G., Muhammad, A.B., Aliyu, R. U., Idris, Z. M., Izuagie, T., Umar, K.J., and Sani, N.A. "Extraction and Characterization of Starches from Four Varieties of Mangifera indica Seeds. Journal of Applied Chemistry, vol.3, no.6, pp. 16-23, 2013.

[19] Lawal O.S., Storz, J., Storz, H., Lohmann, D., Lechner, D., Kulicke, M.W. "Hydrogels based on carboxymethyl cassava starch cross-linked with di- or polyfunctional carboxylic acids: Synthesis, water absorbent behavior and rheological characterizations”. European Polymer Journal, vol. 45, pp. 3399-3408, 2009. 
[20] Ballesteros, L.F., Cerqueira, M.A., Teixeira, J.A., Mussatto, S.I.. "Production and physicochemical properties of carboxymethyl cellulose films enriched with spent coffee grounds polysaccharides". International Journal of Biological Macromolecules, vol.106, pp. 647-655, 2018.

[21] Okhamafe A.O., Igboechi A., Obaseki T.O., "Celluloses extracted from groundnut shell and rice husks Preliminary physicochemical Characterization”. Pharmaceutical World Journal, vol. 8, no.4, pp. 120-130, 1991. 